\title{
REPRODUCE DUCHAMP TO RECREATE AND REBUILD THE WOOD ENGINEERING EDUCATION
}

\author{
Carlos Alberto Oliveira de Matos \\ Campus Experimental de Itapeva \\ Universidade Estadual Paulista "Júlio de Mesquita Filho - UNESP \\ carlos@itapeva.unesp.br
}

\section{PURPOSE}

The separation of knowledge in three major areas is enshrined in Brazil for its suitability to the labor market. The focus on Exact Sciences guides the approach to teaching Engineering and important concepts such as creativity and chance are underemphasized.

\section{DESIGN}

Marcel Duchamp has always worked with controllable variables, but leaving open space for the intervention of chance. This information was the starting point for a project with four moments:

- reproduction and individual recording the results of the original experiment Duchamp: throw strings of a meter to the floor (same certain height) getting to chance the task of choosing the way they assume to touch the ground;

- planning activities by the students involving art or entertainment where the concept of chance were evident. This activity, although creative, it should be based on research in the different data sources available. This research did not need be formalized but should avoid exaggerated spontaneity;

- development of the activity in the classroom and discussion with colleagues of the discipline;

- exposure of the resulting activities in the library lobby for the other students of Wood Engineering Course.

\section{OUTCOMES}

Little elaborate reflections resulted from excess desirable involvement in the implementation of activities without the same degree of involvement in research activities that were requested.

\section{IMPLICATIONS FOR THEORY \& PRACTICE}

One goal was to experience art as a process that, although predominantly creative, has space for research, planning and experimentation. Joining inspiration and perspiration in order to contribute to the deconstruction of not constructive dichotomy between theory and practice that permeates the process of education of engineers.

\section{IMPORTANCE}

The transdisciplinary approach of including in the predominantly orthodox teaching of Engineering important concepts employing Statistics and Arts produced many reflections, which can contribute to the improvement of intervention to achieve the expected results.

\section{REFERENCES}

Lopes, P. A. (1999). Probabilidades e Estatística ( $1^{\text {st }}$ ed.). Rio de Janeiro: Reichmann \& Affonso Editores. 